Masayuki Miyabe MD, Shinji Takahashi $M D$, Shigehito Sato MD, Hidenori Toyooka MD

\title{
Thoracic epidural block attenuates cardiovascular response to apnea in rabbits
}

Purpose: Apnea is one of the potential complications during anaesthesia. If sympathetic nerve activity is blocked by epidural anaesthesia, circulatory responses to apnea might change. Our objective was to assess the potential modifying effects of epidural anaesthesia on the cardiovascular responses to apnea in the animals.

Methods: Twenty rabbits anaesthetised with pentobarbital $\left(25 \mathrm{mg} \cdot \mathrm{kg}^{-1} \mathrm{iv}, 8 \mathrm{mg} \cdot \mathrm{kg}^{-1} \cdot \mathrm{hr}^{-1}\right)$ and pacuronium bromide $\left(0.2 \mathrm{mg} \cdot \mathrm{kg}^{-1} \cdot \mathrm{hr}^{-1}\right.$ iv) were randomly assigned to one of two groups: control $(n=10)$ and epidural $(n=10)$. In the control group, $0.6 \mathrm{ml}$ saline, and in the epidural group, $0.6 \mathrm{ml}$ lidocaine $1 \%$ was injected into the epidural space respectively. After mechanical ventilation with $\mathrm{FIO}_{2} 0.4$, apnea was induced by disconnecting the anaesthetic circuit from the endotracheal tube, and mean arterial pressure (MAP), heart rate (HR), and time to cardiac arrest were measured.

Results: Before apnea MAP was lower in the epidural than in the control group $(73 \pm 10 \mathrm{vs} 91 \pm 10 \mathrm{mmHg}$, $P<0.05)$. Heart rate was not different between groups $(264 \pm 36$ vs $266 \pm 24 \mathrm{bpm})$. Mean arterial pressure increased in the control group after apnea, but not in the epidural group. The time to cardiac arrest was less in the epidural group than in the control group ( $420 \pm 67$ vs $520 \pm 61 \mathrm{sec}, P<0.05$ ). Heart rate decreased markedly after apnea in the control group whereas it decreased gradually in the epidural group.

Conclusion: Thoracic epidural anaesthesia attenuated cardiovascular response to apnea and reduced the time to cardiac arrest.

Objectif : L'apnée est une des complications potentielles de l'anesthésie. Si l'activité nerveuse sympathique est bloquée par l'anesthésie péridurale, les réponses circulatoires à l'apnée peuvent être modifiées. Notre objectif était d'évaluer les effets potentiels de l'anesthésie péridurale pour modifier les réponses cardiovasculaires à l'apnée chez des animaux.

Méthodes : Vingt lapins anesthésiés au pentobarbital $\left(25 \mathrm{mg} \cdot \mathrm{kg}^{-1} \mathrm{iv}, 8 \mathrm{mg} \cdot \mathrm{kg}^{-1} \cdot \mathrm{h}^{-1}\right)$ et au pancuronium $\left(0,2 \mathrm{mg} \cdot \mathrm{kg}^{-1} \mathrm{~kg}^{-1} \cdot \mathrm{h}^{-1}\right.$ iv) ont été assignés aléatoirement à deux groupes, le groupe témoin $(n=10)$ et le groupe péridurale $(n=10)$. Dans le groupe témoin, on a injecté $0,6 \mathrm{ml}$ de $\mathrm{NaCl} 0,9 \%$ dans l'espace péridural alors que dans le groupe péridurale on a injecté $0,6 \mathrm{ml}$ de lidocaine $1 \%$. Après ventilation mécanique à $\mathrm{FIO}_{2} 0,4$, l'apnée a été induite en débranchant le tube endotrachéal du circuit anesthésique et on a mesuré la pression artérielle moyenne (PAM) la fréquence cardiaque (FC) et le temps écoulé jusqu'à l'arrêt cardiaque.

Résultats : Avant l'apnée, la PAM était plus basse dans le groupe péridurale que dans le groupe témoin $73 \pm$ 10 vs $91 \pm 10 \mathrm{mmHg}, P<0,05)$. La FC était analogue dans les deux groupes $(264 \pm 36$ vs $266 \pm 24 \mathrm{bpm})$. À la suite de l'apnée, la PAM a augmenté dans le groupe témoin, mais non dans le groupe péridurale. Le délai avant l'arrêt cardiaque était plus court dans le groupe péridurale que dans le groupe témoin (420 \pm 67 vs $520 \pm$ $6 \mathrm{Isec}, P<0,05)$. La FC a diminué de façon abrupte après l'apnée dans le groupe témoin alors qu'elle a diminué de façon progressive dans le groupe péridurale.

Conclusion : L'anesthésie péridurale thoracique a atténué la réponse cardiovasculaire à l'apnée et a réduit le temps écoulé jusqu'à l'arrêt cardiaque.

From the Department of Anesthesiology, Institute of Clinical Medicine, University of Tsukuba.

Tsukuba, 305, Japan. Phone: 81-298-53-3763; Fax: 81-298-53-3765; E-mail: miyabe@igaku.md.tsukuba.ac.jp. Address correspondence to: Masayuki Miyabe MD.

Accepted for publication January 16, 1998. 


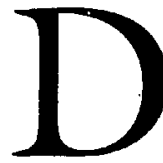

URING epidural anaesthesia, catecholamine release during hypoxia, ${ }^{1}$ hypercapnea ${ }^{2,3}$ or hypotension ${ }^{4}$ is prevented and the presser responses are diminished or converted to a depressor response. Thus, the cardiovascular response to apnea may be affected by epidural anaesthesia. We tested the hypothesis that epidural anaesthesia attenuated the cardiovascular response to acutely induced apnea and reduced the time to cardiac arrest.

\section{Methods}

\section{Preparation}

After approval by the Animal Care and Use Committee, anaesthesia was induced in Japanese White rabbits (2.5 to $3.5 \mathrm{~kg}$ ) with $25 \mathrm{mg} \cdot \mathrm{kg}^{-1}$ pentobarbital $i v$. The trachea was cannulated for mechanical ventilation. Supplemental oxygen $\left(\mathrm{FIO}_{2} 0.4\right)$ was administered to maintain arterial $\mathrm{PaO}_{2}>100 \mathrm{mmHg}$. After tracheotomy. anaesthesia was maintained with $8 \mathrm{mg} \cdot \mathrm{kg}^{-1} \cdot \mathrm{hr}^{-1}$ pentobarbital and pancuronium $\left(0.2 \mathrm{mg} \cdot \mathrm{kg}^{-1} \cdot \mathrm{hr}^{-1}\right.$ pancuronium. The femoral arteries were cannulated for blood pressure and heart rate (HR) measurement and blood sampling. The femoral vein was cannulated for administration of fluids and drugs. Mean arterial pressure (MAP) was measured through the femoral arterial catheter, and HR was determined from the arterial pressure signal. An epidural catheter was placed by removing the 9 th or 10th thoracic spinous process. The ligamentum flavam was exposed and dissected in the midline, and a catheter $(0.63 \mathrm{~mm}$ outer diameter) was inserted through the gap and was advanced $5 \mathrm{~cm}$ cephalad into the epidural space.

\section{Protocol}

After an interval of at least one hour for stabilisation of measured parameters the rabbits were randomly divided into two groups: epidural group $(n=10)$ or control group $(n=10)$. In the epidural group, $0.6 \mathrm{ml}$ lidocaine $1 \%$ and in control group, $0.6 \mathrm{ml}$ saline was injected via the epidural catheter.

Fifteen to twenty minutes after epidural injection baseline MAP, HR measurement and blood gas analysis (BGA) were performed. Then, apnea was induced by disconnecting anaesthetic circuit from the endotracheal tube. Haemodynamic data were monitored continuously until cardiac arrest was observed on arterial pressure tracing. Arterial blood samples for BGA, were collected and every minute after apnea until cardiac arrest. In six animals in each group plasma epinephrine and norepinephrine concentrations were measured before and five minutes after apnea. The time from the start of apnea to cardiac arrest was measured.
At the completion of each experiment, the spine was dissected to confirm that the catheter was properly placed in the epidural space. The extent of epidural solution spread was identified by the stain obtained by postmortem epidural injection of $0.6 \mathrm{ml}$ black ink.

\section{Data analysis}

Results are expressed as mean $\pm \mathrm{SD}$. Data were evaluated by analysis of variance for repeated measures (ANOVA) or two way ANOVA and, as a post hoc test, the Fisher PLED test was performed. Plasma cathecolamine concentrations were compared using unpaired $t$ test. Findings were considered significant if $P<0.05$.

\section{Results}

\section{Extent of injectate spread}

On average, the catheter tip was located at the $T_{5-6}$ disc in the lidocaine group. The median segmental extent of distribution of black ink within the vertebral canal was $\mathrm{T}_{1-10}$ (range $\mathrm{C}_{2}-\mathrm{T}_{3}$ cephalad and $\mathrm{T}_{8-12}$ caudad).

\section{Cardiopascular effect of epidural block}

Mean arterial pressure before the induction of apnea was less in the epidural group than in the control group $(73 \pm 10 v s 91 \pm 10 \mathrm{mmHg}, P<0.05$, Figure 1$)$. Heart rate was not different between groups (264 \pm 36 ps $266 \pm 24$ bpm, Figure 2).

\section{Effect of apnea on the cardiovascular response after epidural block}

Mean arterial pressure increased after apnea in the control group but not in the epidural group (Figure 1). Heart rate decreased after induction of apnea in both groups, but the change was greater in the control group than in the epidural group (Figure 2). Time to cardiac arrest in the epidural group was less than in the control group (420 \pm 67 vs $520 \pm 61 \mathrm{sec}, P<0.05)$.

\section{Plasma catecholamine concentrations change during apnea}

Both norepinephrine and epinephrine concentradtions increased after apnea and there were no differences between groups (refer to the table on the following page).

\section{Discussion}

Our result showed that 1) Apnea in pentobarbital anaesthetised mechanically ventilated rabbits increased MAP and decreased $H R ; 2$ ) Epidural anaesthesia decreased baseline MAP and prevented the increase in MAP and attenuated the decrease in heart rate after apnea; 3) Epidural anaesthesia reduced the time to cardiac arrest after apnea. 


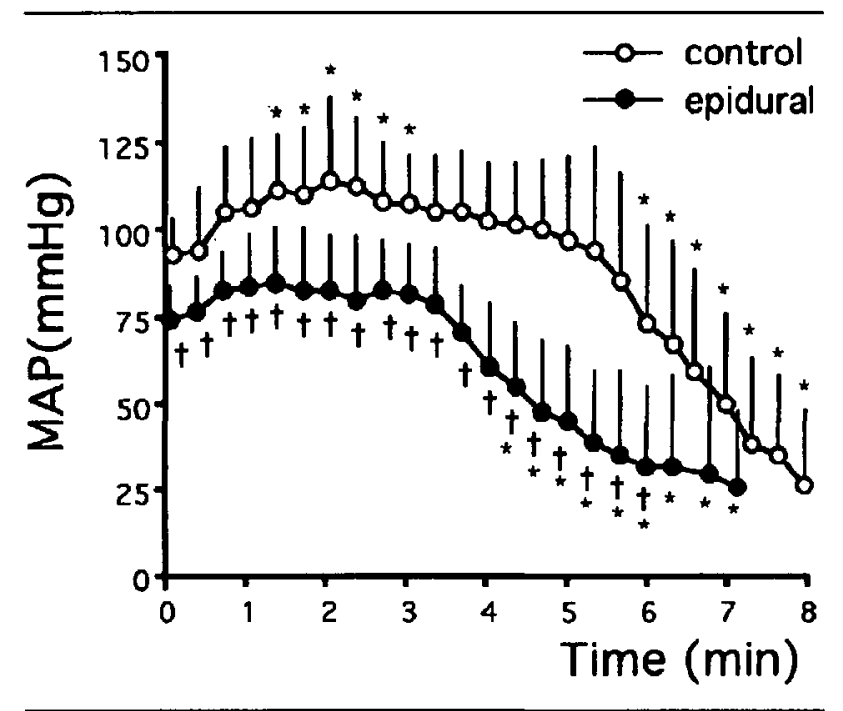

FIGURE 1 Time sequence of mean arterial pressure (MAP) after induction of apnea.

Each value represents the mean $\pm S D$.

${ }^{\star} P<0.05 v$ s baseline value and ${ }^{\dagger} P<0.05 v s$ control group.

Blood gas analysis during apnea in rabbits revealed sudden decrease of $\mathrm{PaO}_{2}$ and gradual increase of $\mathrm{PaCO}_{2}$. Thus, the initial changes of MAP and HR may be mainly due to hypoxia. Systemic hypoxia increases in MAP and bradycardia when ventilation is maintained constant. ${ }^{5}$ The increase in MAP during hypoxia is mediated by activation of the carotid chemoreceptors and increased sympathetic efferent activity. ${ }^{6}$ On the other hand, the cardiodecelerator effect of the carotid chemoreceptors during hypoxia is largely mediated by increased cardiac parasympathetic efferent activity. ${ }^{6-8}$ In this study epidural anaesthesia prevented the increase in

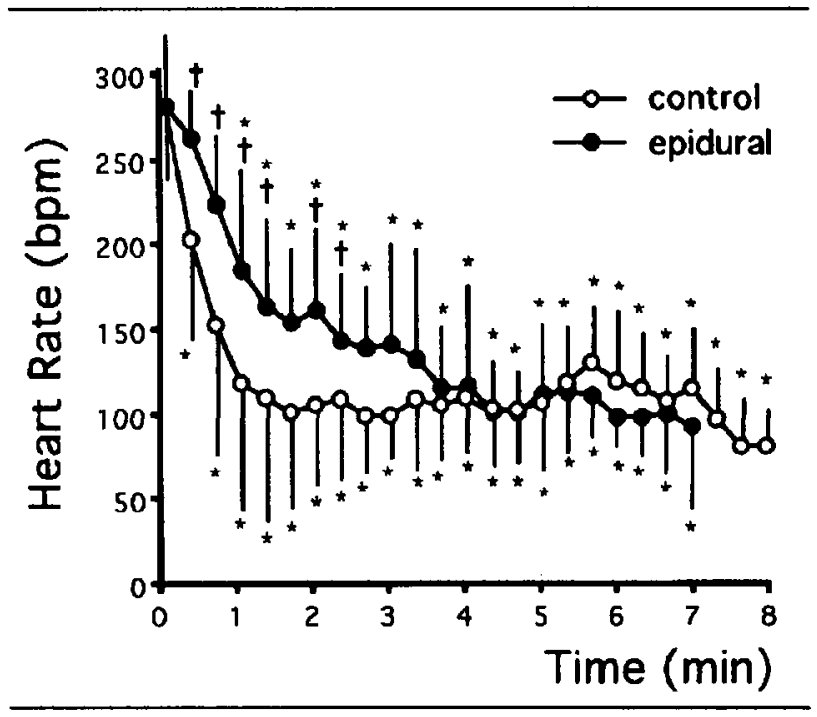

FIGURE 2 Time sequence of heart rate after induction of apnea. Each value represents the mean $\pm S D$. In both groups heart rate decreased rapidly after induction of apnea, however the speed of decrease in control group was greater than that in epidural group. ${ }^{\star} P<0.05$ vs baseline value and $t P<0.05$ vs control group.

MAP during apnea, most likely by preventing sympathetic efferent activity. Epidural anaesthesia also attenuated the bradycardia. It might be the pharmacological effect of lidocaine that prevents the parasympathetic nerve activity, because attenuation of decrease of $H R$ during hypoxia is seen after intramuscular lidocaine. ${ }^{9}$

Plasma catecholamine concentrations at five minutes after induction of apnea both in the control and the epidural group varied among individual animals and there were not statistically significant difference between groups. Mean arterial pressure in the epidural group after induction of apnea was lower than in con-

TABLE Blood Gas Analyses in Control (C) and Epidural (E) group

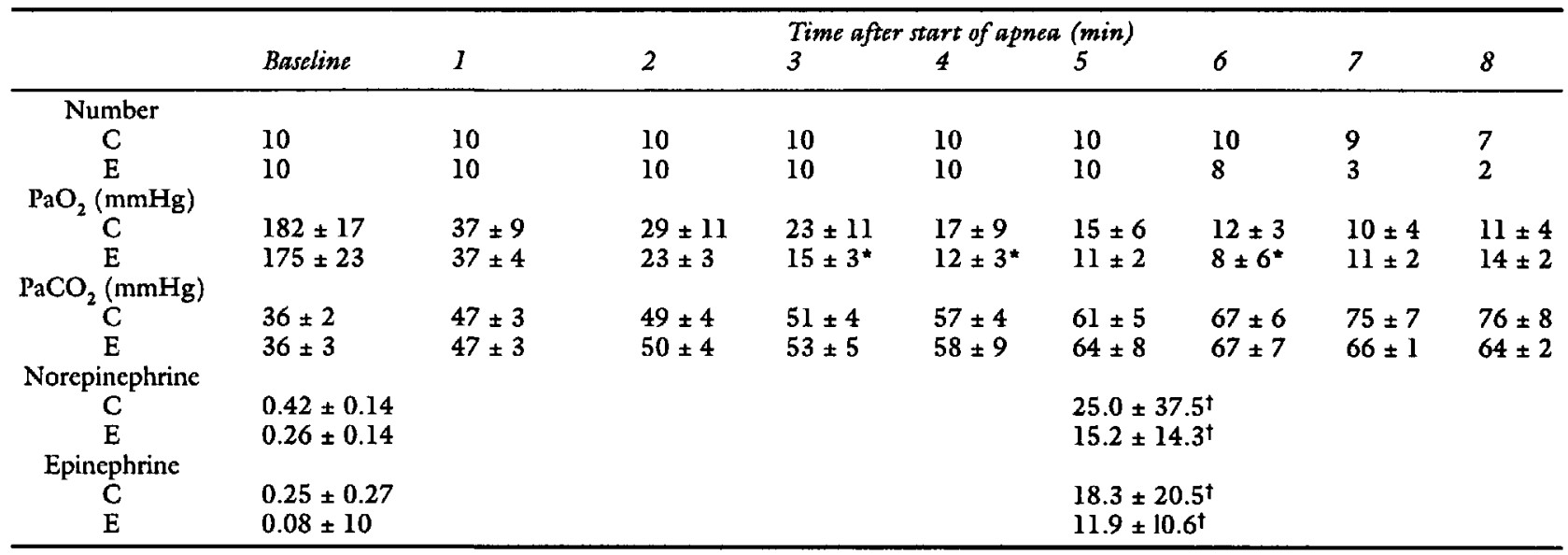

Data are mean \pm SD. ${ }^{*} P<0.05 p s$ control, ${ }^{\dagger} P<0.05$ ps baseline. 
trol group. This means that the physiological stress was more severe in the epidural group and the stimulation to release catecholamine might have been larger in the epidural group. The other possibility is that epidural block which we performed in this study was not complete enough to prevent sympathetic response to apnea. Even if catecholmine release were not blocked completely in this study, sympathetic blockade interfered with intrinsic compensatory reflexes and the time to arrest must have been decreased. If the sympathetic nerve was blocked completely the cardiac arrest time must have been much less in the epidural group.

In summary, our results show that thoracic epidural anaesthesia in pentobarbital anaesthetised mechanically ventilated rabbits: 1) abolishes the increase in MAP and attenuated the decrease of HR after induction of apnea; 2) shortens the time to cardiac arrest after anpea. The changes in cardiovascular vital signs in response to apnea are blunted when spinal sympathetic outflow is blocked by epidural anaesthesia.

\section{References}

1 Peters J, Kutkuhn B, Medert HA, Schlaghecke R, Schüttler J, Arndt JO. Sympathetic blockade by epidural anesthesia attenuates the cardiovascular response to severe hypoxemia. Anesthesiology 1990; 72: 134-44.

2 Shibata K, Futagami A, Taki $\Upsilon$, Kobayasbi $T$. Epidural anesthesia modifies the cardiovascular response to marked hypercapnia in dogs. Anesthesiology 1994; 81: 1454-60.

3 Stevens RA, Lineberry PJ, Arcario TJ, Bacon GS, Cress $L W$. Epidural anaesthesia attenuates the catecholamine response to hypoventilation. Can J Anaesth 1990; 37: 867-72.

4 Sbibata K, Yamamoto $\Upsilon$, Murakami S. Effects of epidural anesthesia on cardiovascular response and survival in experimental hemorrhagic shock in dogs. Anesthesiology 1989; 71: 953-9.

5 Kontos HA, Mauck HP Jr, Richardson DW, Patterson $J L J r$. Mechanism of circulatory responses to systemic hypoxia in the anesthetized dog. Am J Physiol 1965; 209: 397-403.

6 Kontos $H A$, Vertropec GW, Richardson DW. Role of carotid chemoreceptors in circulatory response to hypoxia in dogs. J Appl Physiol 1970; 28: 561-5.

7 O'Donnell CP, Bower EA. Heart rate changes evoked by hypoxia in the anaesthetized, artificially ventilated cat. Exp Physiol 1992; 77: 271-83.

8 Kollai $M$, Koizumi $K$. Cardiovascular reflexes and interrelationships between sympathetic and parasympathetic activity. J Auton Nerv Syst 1981; 4: 135-48.
9 Hogan QH, Kulier A, Bosojak ZJ, Kampine JP. Sympathetic and mesenteric venous responses to baroreceptor or chemoreceptor stimulation during epidural anesthesia in rabbits. Anesthesiology 1996; 85: 1413-21. 